\title{
ANALISIS FAKTOR BAURAN PEMASARAN YANG MEMPENGARUHI KEPUASAN NASABAH SEHINGGA TERCIPTA WORD OF MOUTH POSITIF DI PT. BANK MUAMALAT INDONESIA, TBK CABANG MEDAN
}

\author{
Suryani \\ Dosen Jurusan Syariah Sekolah Tinggi Agama Islam Negeri (STAIN) \\ Malikussaleh Lhokseumawe - Aceh \\ suryapijar@yahoo.com
}

\begin{abstract}
This study attempts to determine the effect of customer satisfaction in the context of the marketing mixof positive word of mouth customers of PT. Bank Muamalat Indonesia, Tbk Medan Branch. Number of questionnaires was collected as many as 50 questionnaires respondent. Analysis technique used was factor analysis followed by discriminant analysis with program of SPSS version 17.0.

Based on factor analysis, it is known that one factor called location was proved to be inaccurate (correlation value $<0.5$ ) so that it is excluded from the model. Canonical correlation is obtained for 0.593 with a significance of 0.003 . It can be concluded that 35.20\% of the variation of positive word of mouth can be explained by the variable of discriminant Product, Promotion, Price, People, Physics and Process.
\end{abstract}

Keywords: Positive Word of Mouth, Customer Satisfaction, Marketing Mix.

\begin{abstract}
Abstrak
Penelitian ini mencoba untuk mengetahui pengarub kepuasan nasabah dalam konteks bauran pemasaran terhadap word of mouth positif nasabah PT. Bank Muamalat Indonesia, Tbk Cabang Medan. Jumlah kuesioner yang berhasil dikumpulkan sebanyak 50 kuesioner/responden. Teknik analisis yang digunakan adalab analisis faktor dilanjutkan analisis diskriminan dengan bantuan program SPSS versi 17.0.

Berdasarkan analisis faktor ditemukan bahwa satu faktor yaitu place (lokasi) terbukti tidak valid (nilai korelasi $<0.5$ ) sehingga dikeluarkan dari model. Hasil canonical correlation diperoleb sebesar 0.593 dengan signifikansi sebesar 0.003. Dengan demikian dapat disimpulkan babwa $35.20 \%$ variasi word of mouth positif dalam bentuk dapat dijelaskan oleh variabel diskriminan Product, Promotion, Price, People, Physic dan Process.
\end{abstract}

Kata kunci: Word of Mouth Positif, Kepuasan Konsumen, Marketing Mix. 


\section{Pendahuluan}

Industri jasa pada saat ini merupakan sektor ekonomi yang sangat besar dan tumbuh sangat pesat. Pertumbuhan tersebut selain diakibatkan oleh pertumbuhan jenis jasa yang sudah ada sebelumnya, juga disebabkan oleh munculnya jenis jasa baru, sebagai akibat dari tuntutan dan perkembangan teknologi. Dipandang dari konteks globalisasi, pesatnya pertumbuhan bisnis jasa antar negara ditandai dengan meningkatnya intensitas pemasaran lintas negara serta terjadinya aliansi berbagai penyedia jasa di dunia. Perkembangan tersebut pada akhirnya mampu memberikan tekanan yang kuat terhadap perombakan regulasi, khususnya pengenduran proteksi dan pemanfaatan teknologi baru yang secara langsung akan berdampak kepada menguatnya kompetisi dalam industri (Lovelock dikutip oleh Tjiptono, 2006).

Implikasi penting dari fenomena ini adalah semakin tingginya tingkat persaingan, sehingga diperlukan manajemen pemasaran jasa yang berbeda dibandingkan dengan pemasaran tradisional (barang). Zeithaml and Bitner (dikutip oleh Tjiptono, 2005) menyatakan bahwa pemasaran jasa adalah mengenai janji yang dibuat kepada pelanggan dan harus dijaga.

Bagi dunia perbankan yang merupakan badan usaha yang berorientasi profit, kegiatan pemasaran sudah merupakan suatu kebutuhan utama dan sudah merupakan suatu keharusan untuk dijalankan. Tanpa kegiatan pemasaran jangan diharapkan kebutuhan dan keinginan pelanggannya akan terpenuhi. Oleh karena itu, bagi dunia usaha apalagi seperti usaha perbankan perlu mengemas kegiatan pemasarannya secara terpadu dan terusmenerus melakukan riset pasar. Pemasaran harus dikelola secara profesional, sehingga kebutuhan dan keinginan pelanggan akan segera terpenuhi dan terpuaskan. Pengelolaan pemasaran bank yang profesional inilah yang disebut dengan nama manajemen pemasaran bank.

Salah satu strategi pemasaran yang selalu menjadi fenomena yang menarik untuk dibicarakan adalah Word of Mouth (WOM) atau biasa disebut dengan promosi dari mulut ke mulut. Beberapa pemasar mempunyai pandangan skeptis dan memandang rendah 
promosi semacam ini, karena seringkali promosi ini membutuhkan opinion leaders yang sulit ditemui. Selain itu WOM cenderung lebih sulit dikontrol. Padahal WOM bisa jadi lebih efektif dibandingkan iklan. Beberapa perusahaan yang sukses menggunakan WOM adalah Jco Donut, Google atau You Tube dan hampir dua per tiga dari keseluruhan penjualan yang terjadi di Amerika dipengaruhi oleh promosi WOM baik secara langsung atau tidak, menurut Kinsey (dalam Praswati, 2009:2).

Studi yang dilakukan oleh Roper ASW juga menunjukkan bahwa sekitar 10 persen dari penduduk Amerika mempunyai kekuatan dan mampu mempengaruhi kebiasaan dari 90 persen pihak lain. Sedangkan efektivitas dari promosi WOM telah meningkat dan bertumbuh sebesar satu setengah kali secara rata-rata sejak tahun 1977 (Mulyadi: 2007). Penelitian terdahulu menunjukkan bahwa konsumen yang puas akan memberitahukan kepada 3 atau 5 orang lain tentang pengalamannya (Heskett et.al.: 1997), sedangkan konsumen yang tidak puas akan memberitahukan kepada 10 sampai 11 orang (Harrison-Walker: 2001).

Hal ini memperlihatkan bahwa konsumen lebih sering menceritakan ketidakpuasan terhadap suatu barang atau jasa dibandingkan kepuasannya. Sehingga pemasar perlu memperhatikan WOM negatif dari perusahaannya yang pada akhirnya akan mempengaruhi citra perusahaan (dalam Praswati, 2009:2).

\section{Pemasaran Lewat Word of Moutb}

Word of Mouth (WOM) didefinisikan sebagai komunikasi positif tentang penawaran perusahaan jasa, secara positive komunikasi Wordof Mouth(WOM) dianggap sebagai kunci keberhasilan (Freiden dan Goldsmith, 1988; Hennig-Thurau etal, 2002; Harrison-Walker, 2001, dalam Sandy Ng, et.al, 2011:134). Sebagai sumber informasi, WOM positif merupakan masukan yang kuat untuk membuat keputusan. Dengan WOM konsumen akan lebih banyak pemasar yang dihasilkan, komunikasi yang dirancang untuk mendapatkan perhatian dan mengubah perilaku, WOM menonjol sebagai sumber informasi yang sangat terpercaya. 
Kata dari mulut ke mulut membantu dalam menarik pelanggan baru yang penting untuk keberhasilan jangka ekonomi suatu perusahaan panjang (Hennig-Thurau, et al., 2002). Hal ini juga berfungsi untuk mengurangi disonansi kognitif untuk pelanggan yang sudah ada (Wangenheim, 2005). Karena disonansi kognitif, yang dialami oleh individu, atas perhatian telah membuat keputusan yang salah (Festinger, 1957), pelanggan menyebar WOM ketika mereka mencoba untuk meyakinkan diri dari keputusan pembelian yang mereka buat (Wangenheim, 2005). Terbukti, WOM adalah salah satu strategi yang digunakan oleh pelanggan untuk mengurangi disonansi pasca keputusan mereka (dalam Sandy Ng, et.al, 2011:134).

Word of Mouth terutama penting bagi penyedia layanan yang ditawarkan sebagian besar berwujud, dan pengalaman atau kepercayaan berbasis. Dalam layanan ini pelanggan sangat bergantung pada nasihat dan saran dari orang lain yang mengalami layanan (Kinard dan Capella, 2006). Selanjutnya, konsumen sering percaya satu sama lain lebih dari mereka percaya komunikasi dari perusahaan, sehingga menyoroti pentingnya WOM (Zeithaml dan Bitner, 1996). Sementara literatur mengakui pentingnya WOM, penelitian memeriksa anteseden WOM dan terutama dampak dari pelanggan-karyawan hubungan dan persepsi kualitas pelayanan pada niat WOM, tetap terbatas (Gremler et al., 2001, dalam Sandy Ng, dkk:134-135).

Berdasarkan berbagai penjelasan di atas, word of mouth dapat dinyatakan sebagai komunikasi interpersonal antara dua bahkan lebih individu seperti anggota kelompok referensi atau konsumen dan tenaga penjual. Rekomendasi dari mulut ke mulut merupakan salah satu faktor penting yang berpengaruh terhadap keputusan seseorang dalam membeli suatu produk. Word of mouth lebih berperan dalam perkembangan pasar suatu bisnis jasa dibandingkan bisnis produk.

Keberhasilan suatu perusahaan berdasarkan keahliannya dalam mengendalikan strategi pemasaran yang dimiliki. Konsep pemasaran mempunyai seperangkat alat pemasaran yang sifatnya dapat dikendalikan yaitu yang lebih dikenal dengan konsep bauran 
pemasaran (marketing mix). Kotler (2000:15) mendefinisikan mengenai bauran pemasaran sebagai: "Bauran pemasaran adalah seperangkat alat pemasaran faktor yang dapat dikendalikan Product, Price, Promotions, Place yang dipadukan oleh perusahaan untuk menghasilkan respon yang diinginkan dalam pasar sasaran. Sementara Saladin (2003:3) memberikan definisi: "Bauran pemasaran ( marketing mix) adalah serangkaian dari variabel pemasaran yang dapat dikuasai oleh perusahaaan dan digunakan untuk mencapai tujuan dalam pasar sasaran. Sehingga bauran pemasaran (marketing mix) dapat diartikan sebagai perpaduan seperangkat alat pemasaran yang sifatnya dapat dikendalikan oleh perusahaan sebagai bagian dalam uapaya mencapai tujuan pada pasar sasaran.

Beberapa penelitian terdahulu yang membahas mengenai faktor yang mempengaruhi komunikasi word of mouth antara lain Sweneey, et.al (2007, 2008), Chaniotakis dan Lymperopoulos (2009), Sandy Ng, et.al (2011), dan Wang, (2011). Sweneey, et.al (2008) melakukan penelitian untuk mengeksplorasi faktor-faktor yang cenderung untuk meningkatkan kemungkinan bahwa penerima kata positif dari mulut ke mulut (word of mouth positif) mungkin dipengaruhi promosi, khususnya dalam lingkungan layanan profesional. Chaniotakis dan Lymperopoulos (2009) menggunakan pendekatan model Parasuraman et.al yaitu menggunakan variabel SERVQUAL sebagai faktor yang mempengaruhi word of mouth. Penelitian Sandy Ng, et.al (2011) menyoroti peran penting persepsi pelanggan pada kualitas teknis, fungsional dan kualitas hubungan pada sektor kesehatan. Wang, (2011). Hasil penelitian menunjukkan bahwa persepsi kualitas pelayanan dan niat beli yang dipengaruhi oleh word of mouth positif.

Dalam sebuah penelitian, Babin, et.al (2005) yang berjudul "Modeling consumer satisfaction and word-of-mouth: restaurant patronage in Korea", word of mouth diukur berdasarkan tiga indikator yaitu niat untuk mengatakan hal-hal positif kepada orang lain, merekomendasikan kepada konsumen lain, dan mendorong teman-teman dan kerabat untuk mengunjungi.

Berdasarkan uraian penelitian terdahulu terlihat bahwa aspek kunci yang mempengaruhi word of mouth positif pelanggan 
adalah kepuasan atas jasa atau pelayanan yang diberikan oleh perusahaan yang dalam hal ini adalah sektor perbankan. Penelitian terdahulu umumnya menggunakan konsep kualitas pelayanan sebagai tolak ukur kepuasan pelanggan, yang dalam penelitian ini penulis mencoba mengevaluasi kepuasan nasabah dari sisi bauran pemasaran (marketing mix).

Seperti diketahui, bauran pemasaran pada sektor jasa dikenal dengan istilah 7P's. Dalam upaya pembentukan kualitas layanan yang baik, biasanya jasa perbankan akan menggunakan kerangkan bauran pemasaran yang telah dikembangkan atau biasa disebut 7 P. (1). Produk/Jasa (Product and Services); (2). Lokasi (Place); (3). Proses (Process); (4). Partisipasi (Participant); (5). Lingkungan Fisik (Physical Surrounding); (6). Harga (Price); (7). Promosi (Promotion). Semakin bermutu dan tinggi nilai yang dihantarkan kepada pelanggan maka semakin kuat fondasi tersebut. Mutu layanan perbankan dapat disebut sebagai kemampuan dan kemauan perusahaan untuk melakukan proses dan aktivitas identifikasi, analisis dan responsif atas setiap harapan dan kebutuhan pelanggan akan jasa perbankan (Cristobal et.al.: 2007).

Bertitik tolak dari uraian di atas maka penelitian ini selanjutnya akan menganalisis kepuasan nasabah dari sisi bauran pemasaran pada PT. Bank Muamalat Indonesia, Tbk Cabang Medan dan dampaknya terhadap word of mouth positif nasabah.

Teori mengenai keterkaitan antara kepuasan dengan word of mouth dinyatakan oleh Tjiptono dan Gregorius (2004:140) yang mengatakan pelanggan yang puas akan berakibat pada terjadinya komunikasi mulut ke mulut (gethok tular) positif yang berpotensi menarik pelanggan baru; selain itu persepsi pelanggan dan publik terhadap reputasi perusahaan semakin positif. Hal ini didukung oleh penelitian Sweeney, et.al (2007, 2008), Chaniotakis dan Lymperopoulos (2009), Sandy Ng, et.al (2011), Wang(2011), Setyawati (2009), Widyaswati (2010), yang berhasil menemukan adanya keterkaitan antara kepuasan dan komunikasi word of mouth pelanggan. Dengan demikian, berdasarkan penelitian-penelitian ini maka dapat dinyatakan bahwa kepuasan dapat meningkatkan komunikasi word of mouth pelanggan. 


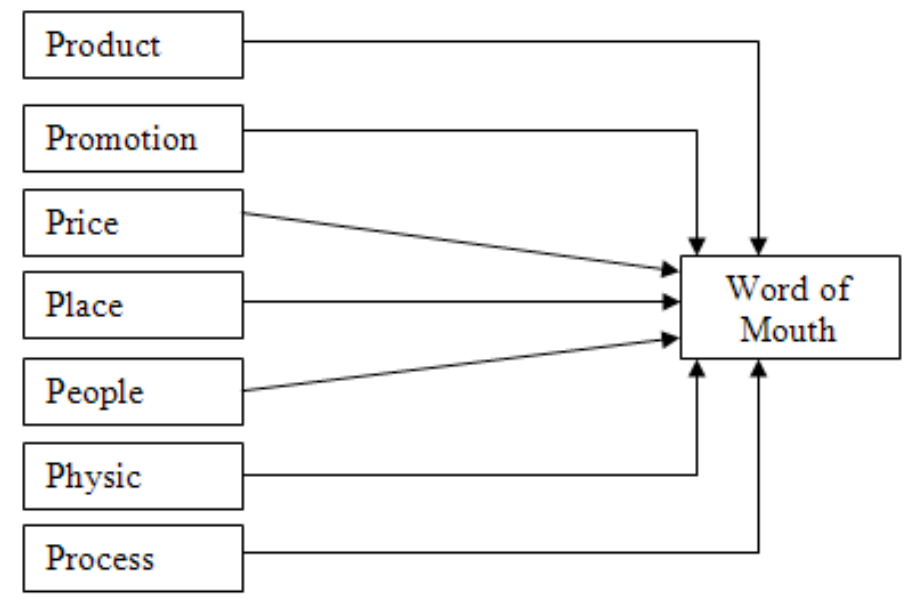

Gambar: 1

\section{Kerangka Pikir Penelitian}

Berdasarkan kerangka pikir di atas selanjutnya dikembangkan hipotesis sebagai berikut:

1. H1: Product berpengaruh terhadap word of mouth positif nasabah.

2. H2: Promotion berpengaruh terhadap word of mouth positif nasabah.

3. H3: Price berpengaruh terhadap word of mouth positif nasabah.

4. H4: Place berpengaruh terhadap word of mouth positif nasabah.

5. H5: People berpengaruh terhadap word of mouth positif nasabah.

6. H6: Physic berpengaruh terhadap word of mouth positif nasabah.

7. H7: Process berpengaruh terhadap word of mouth positif nasabah.

\section{Metode Penelitian}

Penelitian ini merupakan merupakan penelitian kuantitatif dengan menggunakan metode survei. Penelitian survei dilakukan pada populasi besar maupun kecil, tetapi data yang dipelajari adalah data dari sampel yang diambil dari populasi tersebut, sehingga ditemukan kejadian-kejadian relatif distribusi, dan hubungan- 
hubungan antar variabel, sosiologis maupun psikologis (Kerlinger dalam Sugiyono: 2007). Dalam penelitian ini akan dilakukan survey pada sejumlah nasabah pada PT. Bank Muamalat Indonesia, Tbk Cabang Medan. Berdasarkan tingkat ekplanasinya, penelitian ini dikategorikan penelitian korelasional dimana penelitian dilakukan untuk mengetahui hubungan antar variabel yang dihipotesiskan dalam penelitian.

\section{Populasi dan Sampel}

Teknik sampling yang digunakan dalam penelitian ini adalah accidental sampling atau convenience sampling yaitu siapa saja yang secara kebetulan bertemu dengan peneliti yang dijumpai ditempat survei, bila dipandang konsumen yang kebetulan ditemui itu cocok sebagai sumber data (Sugiyono, 2007). Pengambilan sampel akan berhenti setelah terpenuhinya range waktu yaitu selama 5 hari dan diperoleh jumlah sampel sebanyak 50 responden.

Data primer dalam penelitian ini dikumpulkan melalui pengisian kuisioner yaitu dengan memberikan daftar pertanyaan untuk diisi oleh responden. Teknik pengisian kuesioner ini memberikan tanggung jawab kepada setiap responden untuk menjawab setiap pertanyaan yang diajukan oleh peneliti dalam daftar pertanyaan. Data sekunder dalam penelitian ini antara lain berupa data tentang perkembangan perbankan syariah di Indonesia yang diperoleh melalui jurnal, majalah maupun akses data lewat internet maupun informasi-informasi lain yang dapat digunakan sebagai acuan untuk mendukung penelitian mengenai kualitas pelayanan nasabah pada bank.

Kuesioner yang digunakan dalam penelitian ini dibagi menjadi dua bagian. Bagian yang pertama meliputi deskripsi responden yang diminta untuk mengisi kuesioner. Sedangkan bagian kedua dari kuesioner ini berisi item-item pertanyaan dari masing-masing variabel yang digunakan dalam penelitian ini meliputi variabel kualias pelayanan meliputi aspek bukti langsung, keandalan, daya tanggap, jaminan, empati dan produk yang ditawarkan. Skala yang digunakan dalam angket menggunakan metode Likert (Sugiyono, 2007). Dimana metode Likert memberikan nilai skala untuk tiap alternatif jawaban yang berjumlah 5 kategori. 
Dengan demikian, instrumen itu akan menghasilkan total skor bagi tiap anggota sampel. Semua pernyataan yang memilih alternatifalternatif dibawah ini diberi skor.

Tabel: 1

\section{Operasionalisasi Variabel Penelitian}

\begin{tabular}{|c|c|}
\hline Dimensi & Indikator \\
\hline $\begin{array}{l}\text { Buktilangsung } \\
\text { (Tangible) }\end{array}$ & $\begin{array}{l}\text { 1. Ruangan senantiasa bersih dan nyaman } \\
\text { 2. Penampilan fisik dan kerapian karyawan }\end{array}$ \\
\hline $\begin{array}{l}\text { Keandalan } \\
(\text { Reliability) }\end{array}$ & $\begin{array}{l}\text { 1. Tidak adanya kesalahan dalam transaksi } \\
\text { 2. Ada berbagai pilihan produk dan jasa yang } \\
\text { ditawarkan sehingga nasabah bisa memilih }\end{array}$ \\
\hline $\begin{array}{l}\text { Daya Tanggap } \\
\text { (Responsiveness) }\end{array}$ & 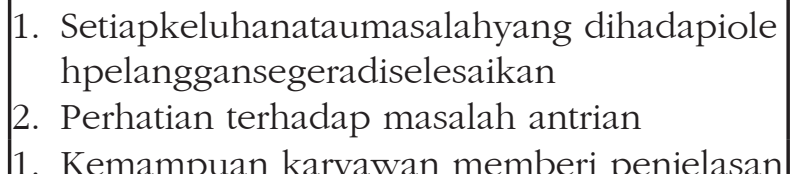 \\
\hline $\begin{array}{l}\text { Jaminan } \\
\text { (Assurance) }\end{array}$ & $\begin{array}{l}\text { mengenai produkyang ditawarkan } \\
\text { 2. Kemampuan karyawan melakukan koreksi } \\
\text { dengan cepat pada waktu terjadi kekeliruan }\end{array}$ \\
\hline $\begin{array}{l}\text { Empati } \\
\text { (Emphaty) }\end{array}$ & $\begin{array}{l}\text { 1. Karyawan memberi ucapan selamat datang } \\
\text { atau sambutan lain ketika pelanggan } \\
\text { dating-pulang } \\
\text { 2. Karyawan mendengarkan dengan baik } \\
\text { setiap keluhan yang disampaikan oleh } \\
\text { nasabah }\end{array}$ \\
\hline & $\begin{array}{l}\text { 1. Produk dan jasa yang diberikan bank } \\
\text { syariah sangat menarik dan inovatif } \\
\text { 2. Jenis produk dan jasa bank syariah sangat }\end{array}$ \\
\hline Produk Tabungan BMI & $\begin{array}{l}\text { beragam sehingga memberikan banyak } \\
\text { pilihan sesuai kebutuhan sava }\end{array}$ \\
\hline & $\begin{array}{l}\text { 3. Istilah-istilah dan nama produk/jasa syariah } \\
\text { sudah akrab ditelinga saya }\end{array}$ \\
\hline & $\begin{array}{l}\text { Apakah anda pernah mengajak/ } \\
\text { merekomendasikan keluarga atau rekan untuk }\end{array}$ \\
\hline Word of mouth Positif & $\begin{array}{l}\text { menjadi nasabah produk Tabungan BMI } \\
\text { Cabang Medan? } \\
\text { Jawaban : Ya/Tidak }\end{array}$ \\
\hline
\end{tabular}

Sumber: Data terolah 


\section{Teknik Analisis Data (Model Analisis)}

Pengujian instrumen terdiri dari dua yaitu uji validitas dan reliabilitas instrument pengumpul data. Validitas adalah suatu ukuran yang menunjukan tingkat-tingkat kevalidan atau kesahihan suatu suatu instrumen (Arikunto, 2006:160). Validitas digunakan untuk mengukur sah atau valid tidaknya suatu kuesioner. Suatu kuesioner dikatakan valid jika pertanyaan pada kuesioner mampu mengungkapkan sesuatu yang akan diukur oleh kuesioner tersebut. Jadi validitas ingin mengukur apakah pertanyaan dalam kuesioner yang sudah kita buat betul-betul dapat mengukur apa yang kita ukur (Ghozali, 2009: 45).

Analisis berikutnya adalah analisis faktor. Uji ini dilakukan untuk pengujian validitas konstruk. Dalam analisis ini akan dilihat seberapa besar korelasi antar faktor satu dengan faktor lain yang menjadi pembentuk variabel. Jika ditemukan korelasi yang cukup kuat di antara faktor-faktor maka dinyatakan faktor tersebut dinyatakan memang sebagai pembentuk variabel. Besaran matrik korelasi yang disepakati untuk analisis faktor adalah 0,5.

Analisis diskriminan adalah metode statistik yang digunakan oleh peneliti untuk membantu mereka memahami hubungan antara "variabel dependen" dan satu atau lebih "variabel independen." Sebuah variabel dependen adalah variabel yang peneliti sedang mencoba untuk menjelaskan atau memprediksi dari nilai-nilai dari variabel independen. Analisis diskriminan mirip dengan analisis regresi dan analisis varians (ANOVA). Perbedaan utama antara analisis diskriminan dan dua lainnya metode ini berkaitan dengan sifat variabel dependen yaitu merupakan variabel kategorial. Hasil penelitian diuraikan sebagai berikut:

Tabel: 2

\section{Test of Equality of Group Mean}

\begin{tabular}{lccccc}
\hline & Wilks' Lambda & F & df1 & df2 & Sig. \\
\hline Product & .795 & 12.381 & 1 & 48 & .001 \\
Promo & .997 & .126 & 1 & 48 & .724 \\
Price & .878 & 6.672 & 1 & 48 & .013 \\
People & .875 & 6.851 & 1 & 48 & .012 \\
Physic & .881 & 6.483 & 1 & 48 & .014 \\
Process & .697 & 20.878 & 1 & 48 & .000 \\
\hline
\end{tabular}

Sumber: data terolah 
Test of Equality of Group Mean digunakan untuk melihat apakah secara univariate ada perbedaan Word of Mouth positif (WOM) dilihat dari 6 variabel independen. Hasil analisis menunjukkan bahwa variabel Product, Price, People, Physic dan Process mampu membedakan (mendeskriminate) pendekatan word of mouth nasabah. Hal ini dapat dilihat dari besaran nilai signifikansi yang kurang dari 0.05. Sedangkan variabel promotion terbukti tidak mampu memberikan perbedaan antara keputusan nasabah untuk merekomendasikan (word of mouth positif).

Persamaan estimasi diskriminan dapat dilihat dari tabel canonical discriminant berikut ini:

Tabel: 3

\section{Canonical Discriminant Function Coefficients}

\begin{tabular}{cc}
\hline & Function \\
\cline { 2 - 2 } & 1 \\
\hline Product & .264 \\
Promo & -.115 \\
Price & .225 \\
People & -.079 \\
Physic & -.158 \\
Process & .849 \\
(Constant) & -7.058 \\
\hline Unstandardized coefficient
\end{tabular}

Sumber: data terolah

Berdasarkan tabel di atas, fungsi diskriminan dapat ditulis sebagai berikut: $\mathrm{Z}=-7.058+0.264$ Product -0.115 Promo + 0.225 Price -0.079 People -0.158 Physic +0.849 Process. Fungsi diskriminan selanjutnya dapat ditulis sebagai berikut (Ghozali, 2009:227): $\mathrm{Z}$ = w1 Product - w2 Promo + w3 Price - w4 People w5 Physic + w6 Process. Dimana w merupakan nilai koefisien yang sudah dinormalkan dengan rumus:

Hasil perhitungan selanjutnya dirangkum sebangai berikut: 
Tabel: 4

Perhitungan Koefisien w

\begin{tabular}{|c|c|}
\hline Koefisien & Nilai \\
\hline W1 & 0.280 \\
W2 & -0.122 \\
W3 & 0.239 \\
W4 & -0.083 \\
W5 & -0.168 \\
W6 & 0.902 \\
\hline
\end{tabular}

Sumber: data terolah

Dengan demikian, fungsi diskriminan diperoleh adalah $\mathrm{Z}=$ $-7.058+0.280$ Product -0.122 Promo +0.239 Price -0.083 People - 0.168 Physic + 0.902 Process. Untuk menguji signifikansi statistik dari fungsi diskriminan tersebut di atas, digunakan multivariate test of significance dengan uji Wilk's Lamda yang diproximasi dengan statistik Chi-Square sebagai berikut:

Tabel: 5

Uji Signifikansi Fungsi Diskriminan Wilks'Lambda

\begin{tabular}{ccccc}
\hline $\begin{array}{c}\text { Test of } \\
\begin{array}{c}\text { Function } \\
\text { (s) }\end{array}\end{array}$ & $\begin{array}{c}\text { Wilks' } \\
\text { Lambda }\end{array}$ & Chi-square & df2 & Sig. \\
\hline 1 & .648 & 19.498 & 6 & .003 \\
\hline \multicolumn{5}{c}{ Sumber: data terolah }
\end{tabular}

Hasil uji Wilk's Lamda pada tampilan tabel di atas menunjukkan nilai sebesar 0.648 atau sama dengan Chi-Square 19.498 dan terjadi secara signifikan dengan perolehan nilai signifikansi 0.003. Dengan demikian dapat disimpulkan bahwa fungsi diskriminan signifikan secara statistik yang berarti nilai rata-rata skor diskriminan untuk dua kelompok nasabah berbeda secara signifikan. 
Tabel: 6

Canonical Correlation Eigenvalues

\begin{tabular}{ccccc}
\hline Function & Eigenvalue & $\begin{array}{c}\text { \%of } \\
\text { Variance }\end{array}$ & $\begin{array}{c}\text { Cumulative } \\
\%\end{array}$ & $\begin{array}{c}\text { Canonical } \\
\text { Correlation }\end{array}$ \\
\hline 1 & $.542^{\mathrm{a}}$ & 100.0 & 100.0 & .593 \\
\hline
\end{tabular}

a. First canonical discriminant funtions were used in the analysis.

Sumber: data terolah

Nilai Canonical Correlation adalah sebesar 0.593. Nilai ini merupakan nilai square canonical correlation $\left(\mathrm{CR}^{2}\right)$ atau identik dengan nilai $\mathrm{R}^{2}$ pada regresi yaitu untuk mengukur variasi antara kedua kelompok nasabah yang merekomendasikan dan yang tidak merekomendasikan. Besaran nilai $\mathrm{CR}^{2}$ adalah $0.593^{2}=0.352$. Dengan demikian dapat disimpulkan bahwa 35.20\% variasi word of mouth positif dalam bentuk merekomendasikan dapat dijelaskan oleh variabel diskriminan Product, Promotion, Price, People, Physic dan Process.

Selanjutnya adalah untuk menilai penting variabel diskriminan dan arti dari fungsi diskriminan, dapat dilihat dari fungsi diskriminan standard sebagai berikut:

Tabel: 7

Nilai Standar Fungsi Diskriminan Standardized Canonical Discriminant Function Coefficients

\begin{tabular}{cc}
\hline & Function \\
\cline { 2 - 2 } & 1 \\
\hline Product & .369 \\
Promo & -.250 \\
Price & .336 \\
People & -.190 \\
Physic & -.295 \\
Process & .935 \\
\hline
\end{tabular}

Sumber: data terolah

Tampilan nilai diskriminan standard di atas menunjukkan bahwa besarnya koefisien Product 0.369, Promotion - 0.250, Price 0.336, People-0.190, Physic -0.295, dan Process 0.935. Dari hasil 
ini dapat disimpulkan bahwa faktor process merupakan variabel diskriminan yang paling dominan mempengaruhi kecenderungan nasabah untuk merekomendasikan (word of mouth positif), disusul faktor Product dan Price. Tiga faktor ini dapat dinyatakan sebagai faktor terpenting yang mempengaruhi kecenderungan word of mouth positif nasabah dalam bentuk merekomendasikan produk atau layanan perbankan syariah.

Tabel 8.

\section{Struktur Matrix Diskriminan}

\begin{tabular}{cc}
\hline & Function \\
\cline { 2 - 2 } & 1 \\
\hline Product & .896 \\
Promo & .690 \\
Price & .513 \\
People & .506 \\
Physic & .499 \\
Process & .070 \\
\hline Sumber: data terolah
\end{tabular}

Nilai loading dari struktur koefisien adalah menggambarkan kontribusi setiap variabel untuk membentuk fungsi diskriminan. Semakin mendekati 1 nilai absolute dari loading, maka makin tinggi komunalitas antara variabel diskriminan dan fungsi diskriminan. Tampilan struktur koefisien pada tabel di atas menunjukkan bahwa besarnya loading tertinggi adalah faktor Process sebesar 0.896, disusun Product 0.690, People 0.513, Price 0.506, Physic 0.499 dan terakhir adalah Promotion sebesar 0.070.

Nilai loading ini juga dapat diinterpretasikan sebagai tingkat kepuasan nasabah atas faktor-faktor bauran pemasaran, sehingga dapat dinyatakan bahwa faktor Process, Product, People, dan Price merupakan empat faktor yang relatif tinggi $(>0.50)$ diapresiasi oleh responden yang dalam hal ini adalah nasabah.

\section{Analisis}

Sektor Perbankan merupakan salah satu sektor jasa yang memiliki atmosfir persaingan yang ketat, sehingga memaksa mereka 
untuk mengembangkan strategi diferensiasi untuk untuk dapat memenangkan kompetisi, salah satunya adalah melalui word of mouth positif dari konsumen/nasabah. Agar dapat menciptakan word of mouth positif dari nasabah, maka pihak bank perlu meningkatkan kepuasan, dan penelitian ini menggunakan faktorfaktor bauran pemasaran.

Penelitian ini menggunakan konsep bauran pemasaran untuk mengukur kepuasan nasabah dengan 7 faktor meliputi: Product, Promotion, Price, Place, People, Physic, dan Process. Berdasarkan analisis faktor ditemukan bahwa satu faktor yaitu Place (lokasi) terbukti tidak valid (nilai korelasi $<0.5$ ), sedang demikian faktor ini selanjutnya akan dikeluarkan dari model.

Hasil analisis faktor selanjutnya menunjukkan bahwa nilai korelasi masing-masing faktor yaitu: Product 0,751, Promotion 0,783, Price 0.745, People 0.776, Physic 0.831 dan Process 0.794. Sehingga berdasarkan hasil ini dapat diketahui bahwa faktor Physic merupakan faktor yang paling merepresentasikan konsep bauran pemasaran, disusul faktor Process, Promotion, People, Product dan terakhir adalah faktor Price.

Hasil canonical correlation diperoleh sebesar 0.593 dengan signifikansi sebesar 0.003. Dengan demikian dapat disimpulkan bahwa 35.20\% variasi word of mouth positif dalam bentuk merekomendasikan dapat dijelaskan oleh variabel diskriminan Product, Promotion, Price, People, Physic dan Process.

Hasil analisis diskriminan 6 faktor bauran pemasaran menunjukkan bahwa faktor process merupakan variabel diskriminan yang paling dominan mempengaruhi kecenderungan nasabah untuk merekomendasikan (word ofmouth positif), disusul faktor Product dan Price. Tiga faktor ini dapat dinyatakan sebagai faktor terpenting yang mempengaruhi kecenderungan word of mouth positif nasabah dalam bentuk merekomendasikan produk atau layanan perbankan syariah.

Fungsi diskriminan dapat ditulis sebagai berikut: $Z=-7.058$ + 0.264 Product -0.115 Promo + 0.225 Price -0.079 People -0.158 Physic +0.849 Process. Dari gambaran di atas dapat disimpulkan penerimaan hipotesis sebagai berikut: 
H1 : Product berpengaruh terhadap word of mouth positif nasabah: diterima.

H2 : Promotion berpengaruh terhadap word of mouth positif nasabah: ditolak.

H3 : Price berpengaruh terhadap word of mouth positif nasabah: diterima.

H4 : Place berpengaruh terhadap word of mouth positif nasabah: ditolak.

H5 : People berpengaruh terhadap word of mouth positif nasabah: ditolak.

H6 : Physic berpengaruh terhadap word of mouth positif nasabah: ditolak.

H7 : Process berpengaruh terhadap word of mouth positif nasabah: diterima.

Nilai loading dari struktur koefisien adalah menggambarkan kontribusi setiap variabel untuk membentuk fungsi diskriminan. Semakin mendekati 1 nilai absolute dari loading, maka makin tinggi komunalitas antara variabel diskriminan dan fungsi diskriminan. Tampilan struktur koefisien pada tabel 8 menunjukkan bahwa besarnya loading tertinggi adalah faktor Process sebesar 0.896, disusun Product 0.690, People 0.513, Price 0.506, physic 0.499 dan terakhir adalah Promotion sebesar 0.070. Nilai loading ini juga dapat diinterpretasikan sebagai tingkat kepuasan nasabah atas faktor-faktor bauran pemasaran, sehingga dapat dinyatakan bahwa faktor Process, Product, People, dan Price merupakan empat faktor yang relatif tinggi $(>0.50)$ diapresiasi oleh responden yang dalam hal ini adalah nasabah.

\section{Kesimpulan}

Berdasarkan hasil analisis yang dijelaskan sebelumnya diperoleh beberapa kesimpulan antara lain: bahwa satu faktor yaitu place (lokasi) terbukti tidak valid (nilai korelasi < 0.5). Hasil analisis faktor selanjutnya menunjukkan bahwa nilai korelasi masing-masing faktor yaitu: Product 0,751, Promotion 0,783, Price 0.745, People 0.776, Physic 0.831 dan Process 0.794. Sehingga berdasarkan hasil 
ini dapat diketahui bahwa faktor Physic merupakan faktor yang paling merepresentasikan konsep bauran pemasaran, disusul faktor Process, Promotion, People, Product dan terakhir adalah faktor Price.

Dari hasil canonical correlation diperoleh sebesar 0.593 dengan signifikansi sebesar 0.003. Dengan demikian dapat disimpulkan bahwa 35.20\% variasi word of mouth positif dalam bentuk merekomendasikan dapat dijelaskan oleh variabel diskriminan Product, Promotion, Price, People, Physic dan Process. Fungsi diskriminan dapat ditulis sebagai berikut: $\mathrm{Z}=-7.058+0.264$ Product - 0.115 Promo + 0.225 Price -0.079 People -0.158 Physic +0.849 Process. Dari gambaran di atas dapat disimpulkan penerimaan hipotesis sebagai berikut:

a. H1 : Product berpengaruh terhadap word of mouth positif nasabah : diterima.

b. H2 : Promotion berpengaruh terhadap word of mouth positif nasabah : ditolak.

c. H3 : Price berpengaruh terhadap word of mouth positif nasabah : diterima

d. H4 : Place berpengaruh terhadap word of mouth positif nasabah : ditolak.

e. H5 : People berpengaruh terhadap word of mouth positif nasabah : ditolak.

f. H6 : Physic berpengaruh terhadap word of mouth positif nasabah: ditolak.

g. H7 : Process berpengaruh terhadap word of mouth positif nasabah : diterima.

Hasil analisis diskriminan 6 faktor bauran pemasaran menunjukkan bahwa faktor Process merupakan variabel diskriminan yang paling dominan mempengaruhi kecenderungan nasabah untuk merekomendasikan (word of mouth positif), disusul faktor Product dan Price. Tiga faktor ini dapat dinyatakan sebagai faktor terpenting yang mempengaruhi kecenderungan word of mouth positif nasabah dalam bentuk merekomendasikan produk atau layanan perbankan syariah. 
Hasil dari temuan penelitian dapat direkomendasikan beberapa implikasi kebijakan sesuai dengan prioritas yang dapat diberikan sebagai masukan bagi pihak manajemen. Berikut ini diuraikan beberapa saran alternatif yang bersifat strategis yaitu: (1) Berdasarkan hasil penelitian maka disarankan agar kepuasan nasabah untuk dapat terus ditingkatkan untuk meningkatkan word of mouth positif nasabah. Faktor diutamakan yaitu faktor Process merupakan variabel diskriminan yang paling dominan mempengaruhi kecenderungan nasabah untuk merekomendasikan (word of mouth positif), disusul faktor Product dan Price; (2) Faktor Place (lokasi) perlu mendapat perhatian mengingat hasil analisis menunjukkan tidak validnya faktor ini sebagai faktor pembentuk bauran pemasaran. Dengan demikian, disarankan agar pihak manajemen dapat mempertimbangkan perluasan jaringan kantor layanan agar dapat memperluas cakupan area pemasaran sekaligus memudahkan nasabah untuk mendapatkan pelayanan; (3) Penelitian ini menggunakan konsep bauran pemasaran untuk mengukur tingkat kepuasan nasabah sebagai pilot study. Disarankan untuk penelitian mendatang untuk menggunakan konsep kualitas layanan sebagai predictor perilaku word of mouth sebagaimana yang dilakukan oleh Sweeney, et,al (2007, 2008), Chaniotakis dan Lymperopoulos (2009), Sandy Ng, et.al (2011), dan Xuehua Wang, (2011). (4) Penelitian ini terbatas pada sampel yang berjumlah 50 sehingga tidak bisa dilakukan analisis yang lebih kompleks seperti Struktural Equation Modeling. Dengan demikian, disarankan agar penelitian lanjutan untuk membanyak sampel dan menggunakan teknik analisis yang lebih kompleks seperti Struktural Equation Modeling.

\section{Daftar Pustaka}

Arikunto, Suharsimi. 2006. Manajemen Penelitian. Edisi Revisi. Jakarta: Penerbit PT. Rineka Cipta.

Barry J. Babin, Yong-Ki Lee, Eun-Ju Kim, Mitch Griffin, 2005. "Modeling Consumer Satisfaction and Word-of-Mouth: Restaurant Patronage in Korea ".Journal of Services Marketing. Vol. 19 Iss: 3: $133-139$. 
Ghozali. Imam. 2009. Aplikasi Analisis Multiariate dengan Program SPSS. Semarang: BP-UNDIP.

Indah Setyawati. 2009. Analisis Pengarub Kualitas Layanan Dan Kepuasan Pasien Terhadap Words Of Mouth. Studi pada Pasien Rawat Jalan RS. Bhakti Wira Tamtama Semarang. Thesis Program Studi Magister Manajemen Universitas Diponegoro.

Ioannis E. Chaniotakis, Constantine Lymperopoulos. 2009. "Service Quality Effect on Satisfaction and Word of Mouth in the Health Care Industry".Managing Service Quality. Vol. 19 Iss: $2: 229-242$.

Jillian C. Sweeney, Geoffrey N. Soutar, Tim Mazzarol. 2008. "Factors Influencing Word of Mouth Effectiveness: Receiver Perspectives". European Journal of Marketing. Vol. 42 Iss: 3/4: $344-364$.

Kusnendi. 2008. Model-model Persamaan Struktural. Bandung: Alfabeta.

Kotler, Philip. 2002. Manajemen Pemasaran.Edisi Milenium. Jakarta: PT Prenhalindo.

Niels Peter Mols, Per Nikolaj D. Bukh, Jørn Flohr Nielsen. 1999. "Distribution Channel Strategies in Danish Retail Banking". International Journal of Retail \& Distribution Management. Vol. 27 Iss: 1: $37-47$

Sandy Ng, Meredith E. David, Tracey S. Dagger. 2011. "Generating Positive Word-of-Mouth in the Service Experience". Managing Service Quality. Vol. 21 Iss: 2: 133 - 151.

Sugiyono. 2007. Metode Penelitian Administrasi. Bandung: Alfabeta.

Rahmatya Widyaswati. 2010. Analisis Faktor-Faktor Yang Mempengarubi Kepuasan Sehingga Tercipta Word Of Mouth Yang Positif Pada Pelanggan Speedy Di Semarang. Thesis Program Studi Magister Manajemen Program Pasca Sarjana Universitas Diponegoro Semarang.

Sumarwan, Ujang. 2003.Perilaku Konsumen Teori dan Penerapannya Dalam Pemasaran. Jakarta: Ghalia Indonesia.

Tjiptono, Fandy and Gregorius Chandra. 2005. Service, Quality $\&$ Satisfaction. Yogyakarta: Penerbit ANDI. 
Tjiptono, Fandy. 2006. Pemasaran Jasa. Bayumedia: Malang. Xuehua Wang. 2011. "The Effect of Inconsistent Word-of-Mouth During the Service Encounter". Journal of Services Marketing. Vol. 25 Iss: 4: $252-259$. 